\title{
Desenvolvimento subnacional e política externa: a participação dos entes federados na política externa brasileira para questão amazônica
}

\author{
Subnational development and foreign policy: the participation of federated entities in the brazilian foreign \\ policy for the amazon issue
}

DOI: https://doi.org/10.22456/2178-8839. 112129

André Luiz Reis da Silva Universidade Federal do Rio Grande do Sul, Porto Alegre, Brasil reisdasilva@hotmail.com 0

Felipe de Macedo Teixeira Universidade Federal do Rio Grande do Sul, Porto Alegre, Brasil fmt1996@hotmail.com

\section{Resumo}

A presente pesquisa propõe-se, enquanto objetivo geral, a analisar as relações entre o Governo Federal e os entes federados na formação da política externa brasileira (PEB) para a questão amazônica. Para isso, é desenvolvido um estudo quantitativo e qualitativo dos investimentos realizados pelo Banco Interamericano de Desenvolvimento (BID, ou IDB - Inter-american Development Bank) em entes subnacionais da Amazônia Legal no contexto das políticas de Diplomacia Federativa e da Cooperação Internacional Federativa da política externa brasileira. Assim, o artigo terá como problemática central a análise se a dimensão subnacional dos entes federados da Amazônia Legal foi fortalecida através dos investimentos do BID na região em questões ambientais. Os aspectos metodológicos são traçados a partir da abordagem de análise institucional das políticas de engajamento subnacional. Ademais, a análise dos investimentos do BID é realizada por fontes primárias, além de uma revisão bibliográfica acerca de dois debates da Análise de Política Externa (APE), a pluralização de atores, e o caráter de políticas públicas da política externa. Em suma, os resultados da pesquisa apontam para o papel central das políticas de relações federativas do Governo Federal no fortalecimento dos estados da Amazônia Legal em suas ações internacionais e busca por investimentos.

Palavras-chave: Paradiplomacia; Floresta Amazônica; Banco Interamericano de Desenvolvimento;

\section{Abstract}

This research proposes, as a general objective, to analyze the relations between the Federal Government and the federated entities in the formation of the Brazilian foreign policy for the Amazonian question. To this end, it is developed a quantitative and qualitative study of the investments made by the Inter-American Development Bank (IDB) in subnational entities in the Legal Amazon within the context of the policies of Federative Diplomacy and International Federative Cooperation of Brazilian foreign policy. Thus, the article has as a central problem if the subnational dimension of the federated entities of the Legal Amazon was strengthened through the IDB's investments in the region in environmental issues. The methodological aspects are traced from the approach of institutional analysis of subnational engagement policies. In addition, the analysis of the IDB's investments is carried out by primary sources, in addition to a bibliographic review on two debates on Foreign Policy Analysis (FPA), the pluralization of actors, and the character of public policies on foreign policy. In summary, the results of the research point to the central role of the Federal Government's federal relations policies in strengthening the states of the Legal Amazon in their international actions and the search for investments.

Keywords: Paradiplomacy; Amazon rainforest; Inter-American Development Bank; 


\section{Introdução}

A transnacionalização da política é um fenômeno defendido pelas escolas liberais institucionalistas, cujas principais consequências associam-se ao questionamento da divisão clássica de agendas domésticas e externa. Tal caráter “interméstico" que a política passa a ganhar foi instrumentalizado pela subárea das relações internacionais da Análise de Política Externa como meio de estudo das variáveis e determinantes que levam ao processo de decisão e execução das relações exteriores de um país (FIGUEIRA, 2011; HUDSON; VORE, 1995). Neste processo, a paradiplomacia surge como consequência prática e teórica dos processos de interdependência econômica e internacionalização de pautas domésticas. Tendo como uma das principais razões e motivações a ineficácia dos governos centrais de atenderem às demandas regionais/locais, a paradiplomacia surge enquanto instrumento dos governos subnacionais de promoção seu desenvolvimento, de forma a atender suas especificidades.

No caso do Brasil, a ação externa de estados ganha força no final década de 1980 diante da descentralização da política no país e pelo processo de abertura econômica e integração regional, que tanto expôs o mercado doméstico às pressões internacionais, quanto oportunizou aos atores domésticos à busca pela internacionalização enquanto meio de buscar parcerias e oportunidades de interesse subnacional. Adota-se o entendimento defendido por Miklos (2010; 2011), Meirelles (2016) e Banzatto (2015), de que dimensão subnacional brasileira nas relações internacionais ganha força através das políticas adotadas durante os governos Cardoso e Lula da Silva, a Diplomacia Federativa e a Cooperação Internacional Federativa, respectivamente. No entendimento destes autores, ambas políticas fizeram parte de uma mudança de postura do Estado brasileiro perante à paradiplomacia, passando do receio institucional ao apoio e incentivo da ação externa subnacional. A Cooperação Internacional Federativa, principalmente, passou a engajar tais entes federados nas ações da política externa brasileira através de diversos mecanismos de cooperação federativa, dentre os quais a intermediação com instituições financeiras internacionais para investimentos diretos em entes subnacionais foi uma das medidas que ganhou força.

Partindo deste contexto, a questão da preservação da Floresta Amazônica, um dos objetivos da política externa brasileira (PEB) na agenda ambiental, ganha reforço na PEB pela mobilização dos entes federados da Amazônia Legal (estados do Amazonas, Roraima, Rondônia, Pará, Amapá, Acre, Tocantins, Mato Grosso e Maranhão) nos esforços de engajamento internacional. Os esforços intergovernamentais de entes federados são parte da noção de federalismo cooperativo a qual a Constituição Federal de 1988 busca construir na organização do Estado brasileiro. Dentre as atividades paradiplomáticas, a prática de busca de empréstimos e investimentos externos é entendida como elementar na promoção do desenvolvimento local (TAVARES, 2016), e para o entendimento da dimensão subnacional da política externa brasileira. Desta forma, o presente trabalho teve como problemática central responder: a dimensão subnacional da política externa, centrada preservação da Floresta Amazônica, foi fortalecida através dos investimentos do Banco Interamericano de Desenvolvimento na região?

No intuito de prover uma dimensão explicativa mais ampla à problemática estabelecida, propôs-se a hipótese de que as políticas do Estado brasileiro para questão da paradiplomacia e política externa - a Diplomacia Federativa e a Cooperação Internacional Federativa - deram força política e autonomia aos entes da Amazônia Legal, levando, de forma indireta, a um aumento de investimentos do BID na região diretamente nos estados, e fortalecendo a dimensão subnacional da política externa. A escolha desta hipótese permitiu à pesquisa, na medida em que buscou responder a problemática central, direcionar os estudos dos investimentos do BID na região Amazônica a partir das relações federativas e dentro do contexto institucional de construção da política externa brasileira em múltiplos níveis e atores.

A partir do problema e hipótese traçados, a pesquisa teve como objetivo geral analisar como ocorreu a relação entre os entes federados e o Governo Federal para construção da política externa brasileira na questão amazônica. Especificamente, propõem-se: (1) estudar quantitativa e qualitativamente os investimentos realizados pelo BID em entes subnacionais da Amazônia Legal; (2) analisar o papel das instituições da Diplomacia Federativa e da Cooperação 
Internacional Federativa na construção da dimensão subnacional da política externa brasileira. Tomou-se como referencial temporal os anos de 1995-2019, período que marca os principais investimentos do BID na região. Desta forma, a paradiplomacia para os entes subnacionais da Amazônia Legal será instrumentalizada enquanto um meio de promoção do desenvolvimento local. Neste caso, as políticas ambientais confundem-se com as políticas públicas de desenvolvimento social dos estados, e o artigo ilustra como os investimentos realizados na região convergem com tal pensamento, ao associar a proteção ambiental com o desenvolvimento social.

Para desenvolver o problema proposto, a pesquisa utilizou-se da literatura de Análise de Política Externa, tanto pelos estudos pioneiros de ação externa subnacional, no intuito de construir uma base teórica sobre as dinâmicas entre o poder central e o poder local na formação da política externa, quanto pela análise exploratória de como as políticas do Estado brasileiro para a paradiplomacia fortaleceram a dimensão subnacional da política externa. Como bem observa Salomón (2011), nos estudos sobre paradiplomacia o objeto de estudo da APE torna-se o governo subnacional e suas relações com o governo central. Assim, a escolha da APE enquanto abordagem teórica justificou-se na medida em que esta subárea se ocupa dos estudos dos fatores determinantes e variáveis dos processos de tomada de decisão da política externa estatal e suas unidades decisórias neste processo (SALOMÓN; PINHEIRO, 2013), demonstrando-se enquanto perspectiva analítica adequada. A análise desta literatura, realizada a partir da abordagem institucional e, contemplando diferentes gerações dos estudos de paradiplomacia, é cruzada com os dados primários oriundos do BID, de forma a permitir o desenvolvimento de uma discussão teórica que responda a problemática central e à hipótese traçadas.

No aspecto metodológico, uma vez que o problema se inseriu no campo da construção da política externa e relações federativas brasileiras, a pesquisa foi conduzida a partir de uma abordagem de análise institucional com enfoque majoritariamente qualitativo, permitindo o entendimento dos processos, atores e dinâmicas que contemplaram tal dimensão subnacional. As fontes escolhidas contemplaram a necessidade teórico-conceitual proposta. A literatura de base revisada, além de permitir o entendimento das relações entre o ente central e os entes subnacionais, traçou os principais liames das políticas de Diplomacia Federativa e Cooperação Internacional Federativa, cuja análise foi posteriormente contribuída por fontes primárias de dados governamentais.

Ademais, a análise dos investimentos do BID foi realizada de forma qualitativa e quantitativa através de uma pesquisa ao banco de dados disponibilizado pelo Banco em sua base eletrônica, com ênfase na seção de projetos nas áreas de Environment and Natural Disasters. Tal seção é a responsável por englobar projetos financiados pelo Banco na área ambiental. Como primeiro corte, foram analisados os investimentos realizados diretamente nos estados da Amazônia Legal. Em seguida, foram analisados aqueles realizados através do Governo Federal brasileiro para questões da floresta Amazônica. Todos os projetos analisados estão na categoria de já aprovados pelo Banco. Tais cortes permitiram à pesquisa o entendimento da contribuição dos investimentos do Banco tanto em políticas locais quanto nacionais, de forma a testar a hipótese proposta.

Portanto, a pesquisa inseriu-se neste contexto da presença de dois níveis de poder estatal na questão amazônica, o nível regional/local (subnacional) e o nível nacional, a primeira por uma interpretação dirigida pela subsidiariedade e desenvolvimento local, e a segunda pela ótica da soberania nacional. Insere-se assim a pesquisa dentro de dois debates centrais que permeiam a Análise de Política Externa (APE): a pluralização de atores nas relações interno-externo para condução das relações exteriores (FARIA, 2012); e a caracterização de política externa enquanto política pública (MILANI; PINHEIRO, 2013). Tais debates foram parte essencial para condução do desenvolvimento deste trabalho, apontando como a política externa brasileira passa a ganhar uma dimensão subnacional voltada ao desenvolvimento de demandas regionais, com potencial contributivo para consecução dos objetivos nacionais na questão da preservação amazônica. 


\section{Referencial teórico}

Ao analisar a questão da paradiplomacia perante o referencial da Análise de Política Externa, estudos sobre as unidades subnacionais começam a relacionarem-se com tal abordagem a partir dos exames acerca da interação entre os ambientes doméstico e internacional, reconhecendo uma interdependência. A primeira geração de estudos sobre a ação externa de entes subnacionais concentrou-se no possível tensionamento da relação entre o poder local e o poder central (HOCKING, 1997; KEATING, 2004; KINCAID, 1990; LECOURS, 2008), além da busca pela definição teórica sobre o que constitui uma política externa, tendo em vista a necessidade de reavaliação do paradigma estatocêntrico diante do "desafio subnacional”.

Destacaram-se ainda neste debate os trabalhos de Duchacek (1990) e Soldatos (1990), visto que realizam análises a partir de estados federados, de forma que a aplicabilidade de seus estudos sobre o caso do federalismo brasileiro leva este trabalho a focar-se nas contribuições destes dois autores. Ao estudar as possibilidades de convergência das ações internacionais subnacionais e nacionais, Soldatos explicou (1990) que o processo de segmentação da política externa pelos entes subnacionais poderia levar à racionalização desta política externa, ao invés de um processo conflituoso entre os entes do país. Tal racionalização trata-se de um processo de descentralização coordenada na política externa, no qual o ente central aceita e junta forças políticas com os subnacionais para o policy making da política externa, de forma a gerenciar as diversas atividades transgovernamentais a harmonizá-las em suas próprias políticas (SOLDATOS, 1990).

Desta forma, segundo a literatura, a superação deste tensionamento da ação externa subnacional parte da noção de horizontalidade da política externa, defendida por Duchacek (1990). Este último elabora o conceito de combinative foreign policy, propondo uma política externa com o ente central e os locais de forma a alterar os padrões de relacionamento entre estes entes de uma dinâmica vertical à horizontal (DUCHACEK, 1990). O funcionamento do modelo proposto por este último autor passaria pela construção de novas fórmulas institucionais de coordenação e cooperação entre o central e local, no que Hocking (1997) chama de operacionalidade de níveis múltiplos nas arenas subnacionais, nacionais e internacional, também defendido por Cornago (2010) por expressar uma possível complementariedade.

No caso dos estudos da ação externa subnacional no Brasil, as dinâmicas das ações externas dos estados e municípios passam a desafiar o arcabouço institucional que caracterizou o insulamento burocrático do Ministério das Relações Exteriores. Os principais questionamentos acerca deste insulamento utilizam-se da Análise de Política Externa para discutir o déficit democrático derivado do desequilíbrio no processo decisório em política externa no país. Tal discussão foi aprofundada a partir do debate que aproxima a política externa das políticas públicas. Neste, como apontam Milani e Pinheiro (2013), a pluralização de atores, que ocorre tanto pela participação política do Legislativo na política externa, quanto pela presença de diferentes agências e entes subnacionais diretamente pelo poder Executivo, acarreta também em uma diversidade de temas a fazerem parte da agenda externa do país (MILANI; PINHEIRO, 2013).

Neste processo, a transversalidade de temas antes vistos como domésticos, agora passam por um processo de internacionalização da pauta de políticas públicas. Milani e Pinheiro (2013) defendem, desta forma, repensar a política externa como um contínuo entre o nacional e o internacional, diante da diluição das reações de poder entre o plano doméstico e externo (MILANI; PINHEIRO, 2013). Tal contribuição converge com o debate acerca da paradiplomacia e as relações externas do ente central, na medida em que os entes subnacionais são parte deste processo de pluralização de atores nas relações internacionais como, por exemplo, Sartori (2014) aponta para a paradiplomacia no processo de integração do Mercosul. A dimensão subnacional da política externa passou a ganhar reconhecimento pelo Governo Federal a partir da política de Diplomacia Federativa implementada pela gestão de Cardoso em 1995, e tem continuidade na política de Cooperação Internacional Federativa da gestão de Lula da Silva e Rousseff, começando em 2003 (MIKLOS, 2011; MEIRELLES, 2016; BANZATTO, 2015). Partindo deste ponto que o problema da presente pesquisa teve enfoque temático, no intuito de responder como a inserção subnacional, tornou-se uma dimensão dos esforços internacionais do Estado brasileiro de proteção da Floresta Amazônica. 


\section{A Amazônia, a soberania brasileira e as relações federativas}

A questão da soberania brasileira sobre a Amazônia passa por processos de securitização e desecuritização, a depender dos governos e da conjuntura política (SOUZA, 2019), e adquire forte conteúdo na política regional, na medida em que está fortemente ligada a soberania brasileira sobre uma parte significativa de seu território. A antiga visão do Estado brasileiro sobre a Floresta Amazônica é sintetizada pela abordagem estatal durante o período militar, no qual a região ficou em segundo plano na política externa, "diluída na questão geral ambiental" (BEZERRA, 2013, p. 159), até a assinatura do Tratado de Cooperação Amazônica, que traz maior ênfase ao eixo norte-sul da PEB. Tal visão é explicada também por Fearnside (2016) ao apresentar as diversas obras de infraestrutura realizadas na região sem estudos de impactos ambientais, no período do regime militar, permeado pelo pensamento desenvolvimentista. Além disso, como lembra Moreira (2013), o medo da desnacionalização da isolada região amazônica norteou uma política baseada nas noções de soberania e limites fronteiriços por parte do ente central. A principal resposta internacional do país foi a articulação do Tratado de Cooperação Amazônica (TCA) em 1978, que reunia Brasil, Bolívia, Colômbia, Equador, Guiana, Peru, Suriname e Venezuela, mas que careceu de maiores investimentos diplomáticos. O TCA ensejaria a criação da Organização do Tratado de Cooperação Amazônica (OCTA) apenas em 1995 (SILVA, 2009)

Entretanto, a partir dos anos 1990 tem-se inflexão política por parte do Estado brasileiro como uma resposta institucional à desconfiança internacional acerca da capacidade do país de gerir a Floresta, que despertava discursos de internacionalização daquela região enquanto patrimônio da humanidade (BEZERRA, 2013). Além disso, tal período marca a busca por uma nova imagem internacional quanto a questões ambientais do país, refletindo na emergência de uma retórica envolta ao desenvolvimento sustentável e combate ao desmatamento pela política externa brasileira perante à comunidade internacional, que continuou nas décadas seguintes (BEZERRA, 2013). Neste período, as instituições financeiras internacionais passam a ter um papel central no financiamento de projetos de desenvolvimento sustentável na região amazônica (FEARNSIDE, 2016).

Desta forma, Fearnside (2016) apontou que as políticas do Governo Federal para questão ambiental, especificamente quanto à Amazônia, apesar de por vezes inconsistentes e com medidas ainda desenvolvimentistas, representaram avanços no combate ao desmatamento e atuação interministerial sobre questões ambientais. Dentre os pontos de destaque apontados pelo autor (FEARNSIDE, 2016), o papel desempenhado pelos entes subnacionais da região amazônica tem sido essencial para os esforços de preservação da Floresta, por vezes mais ativos do que o ente central brasileiro na busca por financiamento para manutenção florestal. Tendo em vista que a dimensão subnacional da questão amazônica passou a ganhar projeção internacional através das ações de paradiplomacia, a próxima subseção realizou um estudo sobre o desenvolvimento desta dimensão nos estados da Amazônia Legal e as relações com o Governo Federal.

Uma vez que a ação externa subnacional passou a se consolidar a partir dos anos 1990 no país (BRANCO, 2008; NUNES, 2005), o posicionamento do Itamaraty transitou de acomodação institucional e desconforto para aceitação e valorização, através de políticas do ente federal para acomodação institucional deste novo fenômeno. O processo de reconhecimento ganhou ênfase com o discurso do Chanceler Luiz Felipe Lampreia em 1995, no qual reconhece a necessidade do Ministério das Relações Exteriores (MRE) de incorporar a dimensão subnacional das relações externa (BRASIL, 1995). A partir destes termos foi proposta a Diplomacia Federativa, uma política de Estado no qual o MRE estabelecia estruturas institucionais para controle e coordenação da ação internacional subnacional. Tal política manifestou-se institucionalmente pela criação da Assessoria de Relações Federativas (ARF) e os escritórios de representação regional a ela vinculados, ambos em 1997, no intuito de realizar a intermediação entre a Chancelaria e os entes subnacionais, buscando incorporar as demandas dos entes subnacionais à PEB (MIKLOS, 2011).

A partir do governo de Lula da Silva deu-se maior projeção à paradiplomacia, com o estímulo federal e integração à estratégia de desenvolvimento nacional, com a institucionalização da Assessoria de Assuntos Federativos e Parlamentares (AFEPA), ampliando o âmbito da antiga ARF, além da criação da Assessoria de Cooperação Internacional 
Federativa (ACIF), em 2003, e a Subchefia de Assuntos Federativos (SAF), em 2004. A transição em 2003 para o governo Lula foi acompanhada por uma mudança de política quanto à ação dos entes subnacionais. Engajando -se na noção de diálogo federativo como instrumento para o desenvolvimento nacional, consolida-se a Cooperação Internacional Federativa enquanto política de Estado para os entes subnacionais. Tal política passa a refletir a visão governamental da atuação externa dos subnacionais enquanto parte da estratégia de inserção internacional do país, baseando-se no binômio promoção-coordenação (SOMBRA SARAIVA, 2004; MIKLOS, 2011; MEIRELLES, 2016).

No caso dos estados da região amazônica, conforme apontam Gomes Filho e Vaz (2008), o isolamento geográfico e fraca infraestrutura deixaram os entes subnacionais da região amazônica com considerável afastamento da vida nacional, e, ao mesmo tempo, permitiram aproximação com os entes homólogos fronteiriços, principalmente pela similitude geográfica, de forma que a paradiplomacia manifestou-se como alternativa aos padrões de desenvolvimento local (MOREIRA, 2013). Assim, a principal motivação presente que mobilizou os entes subnacionais amazônicos à ação internacional foi à aceleração de seu desenvolvimento regional, buscando assim políticas de melhoria do bem -estar das comunidades locais, ocorrendo, dentre outras ações, pela atração de investimentos estrangeiros (GOMES FILHO, 2011).

Neste cenário, o Estado do Amapá desponta como um dos pioneiros na região a realizar atividades externas, na busca por alternativas de desenvolvimento sustentável por meio de parcerias internacionais diretas, atuando desde 1995, seguido posteriormente pelos estados do Pará, Roraima e Amazonas (GOMES FILHO, 2011). Tais relações com entidades internacionais manifestaram-se primeiramente, com as relações com a Guiana Francesa para desenvolvimento integrado na região através do Programa de Desenvolvimento Sustentável do Amapá (MOREIRA, 2013), patrocinado pelo Banco Interamericano de Desenvolvimento posteriormente.

A expansão e consolidação das ações internacionais dos entes federados da região amazônica ganham força institucional a partir do estabelecimento do Escritório de Representação do Itamaraty na Região Norte (ERENOR) em 1997, que foi uma das articulações propostas pela pioneira política da Diplomacia Federativa, no intuito de apoiar e assessorar os estados e municípios da região em suas atividades internacionais (MOREIRA, 2013; GOMES FILHO, 2011). Desta forma, Gomes Filho observou que desde os anos 1990 todos os estados da Amazônia Legal, salvo Rondônia, criaram aparatos paradiplomáticas na estrutura político-administrativa do Poder executivo estadual, acentuando-se na segunda metade da década de 2000 (GOMES FILHO, 2011, p. 277), na vigência da Cooperação Internacional Federativa.

Ademais, associa-se a valorização ação externa subnacional à emergência do Estado Logístico no Brasil, que teve como política neste setor a Cooperação Internacional Federativa, de forma que a paradiplomacia amazônica passa a ser enxergada enquanto instrumento complementar à política externa do Brasil (MOREIRA, 2013). Desta forma, ainda que a dimensão autônoma da ação externa tenha crescido nas últimas décadas para os estados da Amazônia Legal, tornou -se essencial a ação em parceria com o Governo Federal. Neste ponto, conforme apontam Gomes Filho e Vaz (2008), a “mediação do governo central brasileiro tem sido crucial na interlocução das iniciativas desses governos subnacionais regionais na seara internacional” (GOMES FILHO; VAZ, 2008, p. 162). Tal ponto convergiu com o analisado anteriormente, no qual a política da Cooperação Internacional Federativa é construída no intuito de articulação dos entes subnacionais para ações externa de forma a fortalecer a voz externa do país. Por fim, Gomes Filho (2011) ressaltou que as ações externas dos entes subnacionais da região amazônica estiveram majoritariamente em cooperação com o Governo Federal, através das redes de relações diplomáticas federativas, de forma colaborativa com a diplomacia nacional (GOMES FILHO, 2011).

Pode-se inferir que os entes subnacionais da Amazônia Legal têm ênfase nas relações externas com seus homólogos fronteiriços, porém Gomes Filho e Vaz (2008) apontam para o crescente número de parcerias articuladas com atores internacionais fora do escopo regional. A principal razão apontada pelos autores para ação externa destes estados foi a busca por soluções alternativas às problemáticas socioeconômicas locais, e a temática ambiental aparece associada ao desenvolvimento local. Por sua vez, Moreira (2013) concluiu que os entes subnacionais da Amazônia Legal se 
desenvolveram de forma reativa no aspecto das atividades internacionais, tendo em vista sua reduzida capacidade de influência nas políticas de integração regional do país.

\section{Os investimentos do banco interamericano de desenvolvimento nos entes subnacionais da Amazônia legal para questões ambientais}

Os projetos voltados ao desenvolvimento sustentável da região amazônica datam a década de 1990 no Brasil. Assim, a presente seção, através de uma abordagem descritiva e explicativa, analisou os investimentos realizados pelo BID envolvendo os temas de preservação da floresta Amazônica no país.

Acerca dos investimentos realizados nos estados brasileiros da Amazônia Legal, os estados do Acre, Amapá e Tocantins foram identificados como os beneficiados por projetos de preservação da Floresta. O estado do Acre foi o que registrou o maior número de projetos (cinco). A maior parte destes tiveram como enfoque a preservação de zonas florestais tanto pela modernização do aparato estatal de fiscalização e gerenciamento, quanto pela melhoria nas condições de vida da população local. Destacou-se o projeto The Acre Sustainable Development Program (2013), posteriormente apoiado nos aspectos técnicos pelos projetos Improving Tropical Forest Management as a Strategy for CC mitigation (2011) e Forestry Evaluation in the State of Acre (2019), sendo o primeiro projeto (2013) no valor de 120 milhões de dólares para estabelecer um programa de expansão da economia florestal realizado em parceria com a Secretaria de Estado de Planejamento e com a Secretaria de Estado de Meio Ambiente do Estado do Acre (IDB, 2012). Teve como objetivo auxiliar o estabelecimento de plantações de florestas em áreas degradadas e auxiliar o fortalecimento institucional do governo para fortalecer a administração florestal e provisão eficiente e efetiva dos serviços de manutenção florestal. Os outros dois projetos realizados no estado acreano envolveram medidas de cooperação técnica no intuito de fortalecer a dimensão sustentável do setor extrativista do estado (Strenghthening Extractive Activities Acre - 2019a); e introduzir alternativas econômicas para estabelecimentos de extração baseados na exploração racional através do gerenciamento apropriado que irá garantir a conservação do ambiente nestas áreas (Sustainable Use Tropical Forest in Acre - 2000), este último, com ênfase no desenvolvimento comunitário ${ }^{1}$ (IDB, 2000a).

Quanto aos demais estados beneficiados, o Amapá recebeu o projeto Linking climate change mitigation to community based forest management in Amapá (2013a), de cooperação técnica com objetivo de auxiliar o Governo do Estado do Amapá, através do Instituto Estadual de Florestas, a desenvolver floresta sustentável com base em atividades com objetivo de mitigar as emissões do gás GHC e promover a conservação de serviços bioclimáticos (IDB, 2013a). Dentre as medidas do projeto, incluem-se o treinamento de famílias locais para gerenciamento sustentável da floresta e identificação de fundos para financiamento de longo prazo dos serviços de conservação bioclimáticos (IDB, 2012a, p. 2). Por sua vez, o estado de Tocantins recebeu o projeto de cooperação técnica Environmental Conservation in Tocantins (2019b), com objetivo de estabelecer uma área de proteção como mecanismos de preservação da herança natural e cultural (IDB, 2019b).

Acerca dos projetos realizados pelo Banco diretamente com o Governo Federal brasileiro, percebeu-se uma ênfase em questões envolvendo diretamente o controle do desmatamento da floresta amazônica, tanto pela cooperação técnica quanto pelo financiamento de novos programas. Quanto à primeira modalidade, destacou-se o Low Carbon Agriculture and Avoided Deflorestation for reducing Poverty (2013b), com objetivo de implementar um programa de recuperação de florestas degradadas e pastoreios através da restauração de 37 mil hectares de terra degradada em 7 estados estratégicos na Floresta Amazônica e Atlântica (IDB, 2013b). No mesmo ano foi aprovado o Planning and Capacity Building of the transition Fund for ARPA for Life (2013c), apoiado em questões técnicas pelo Planning and Capacity Building of the Transition Fund for ARPA for Life (2013e) cujo objetivo fora aumentar a manutenção e operação da ARPA, com ênfase nas medidas de mitigação da

\footnotetext{
${ }^{1}$ Está inserido na estratégia do BID para o Brasil, cujo elemento central é auxiliar no gerenciamento ambiental e problemas de recursos naturais, com ênfase na proteção de ecossistemas vulneráveis (IDB, 2000, p. 3)
} 
mudança climática através do combate ao desmatamento. Nestes dois projetos foram previstas medidas de treinamento e provisão de equipamentos e assessoria às atividades da ARPA no Brasil (IDB, 2013d; 2013e).

A mitigação das mudanças climáticas foi parte também dos projetos Assessment of the Impacts of Climate on the Stability of the Amazon Rainforest (2013f), projeto de 1,5 milhões de dólares com objetivo de prover cooperação técnica para assistir o governo brasileiro, através do Ministério de Ciência Tecnologia e Inovação, na avaliação da probabilidade de morte da floresta amazônica e suas implicações potenciais, bem como a relevância da fertilização com carbono para melhorar seus efeitos potenciais (IDB, 2013). Por fim, o combate ao desmatamento teve como projeto principal o Program to Support the Amazon Protection System (2005), também de cooperação técnica, com meios para apoiar o pleno desenvolvimento do Sistema de Proteção da Amazônia (SIPAM) com vistas à sua sustentabilidade financeira, levando em consideração seu papel estratégico como ferramenta governamental e o uso do sistema em benefício da sociedade (IDB, 2005).

Ao analisar tal desenvolvimento institucional dos entes subnacionais da região amazônica perante os investimentos realizados pelo BID, percebeu-se a implementação de projetos de impacto direto e indireto na preservação da floresta amazônica através do Governo Federal (cinco projetos) e dos estados brasileiros (sete projetos). Dentre os pontos de maior destaque na análise, aponta-se para a ênfase em desenvolvimento das comunidades locais e sua qualidade de vida dos projetos ligados ao Acre, Amapá e Tocantins. Tendo em vista que tais entes governamentais estão mais próximos das populações locais de extração e agricultura, a capacitação da população destes estados foi vista como essencial para, consequentemente, ser uma medida de uso sustentável dos recursos da floresta, o que foi reforçado nos relatórios de diversos projetos (BID, 2000;2013; 2013a; 2019;2019a). Quanto aos projetos ligados ao ente central brasileiro, a ênfase mais direta no combate ao desmatamento se expressou através do financiamento de grandes projetos de nível nacional, tais como a ARPA e o SIPAM.

\section{Discussão: a pluralização de atores e políticas públicas}

A hipótese proposta no presente trabalho foi acerca do fortalecimento da dimensão subnacional dos estados da Amazônia Legal como consequência das políticas de incentivo do Governo Federal nas relações externas dos estados. Para testá-la e responder ao problema do fortalecimento da dimensão subnacional pelos investimentos do BID foi realizado em um primeiro momento um levantamento bibliográfico acerca de dois debates centrais da APE; em seguida, uma revisão bibliográfica apresentou brevemente a construção das políticas para a Amazônia, destacando o papel dos entes subnacionais da região nestes esforços, que se utilizam desta questão como um meio de projeção internacional, apoiados pelas estruturas do Governo Federal e do MRE. Por fim, mapearam-se os investimentos do BID na região amazônica feitos em parceria com os estados e com o ente central brasileiro.

Acerca do primeiro debate de APE, da pluralização de atores na política externa brasileira, as evidências levantadas no trabalho explicaram que Diplomacia Federativa e a Cooperação Internacional Federativa atuaram de forma mediata e indireta no fortalecimento da dimensão subnacional para política externa nacional (GOMES, FILHO, 2011; MOREIRA, 2013; GOMES FILHO; VAZ, 2008). Isso ocorreu por dois fatores principais: tais políticas deram maior porosidade institucional do Itamaraty, através das estruturas de apoio e assessorando aos entes subnacionais - dentre eles o ERENOR (FARIA, 2012; MEIRELLES, 2016); e a partir de 2003 os estados e municípios passaram a ser engajados nos esforços e políticas de desenvolvimento do país através de suas ações externas (NUNES, 2005; MIKLOS, 2011). Consequentemente, houve maior inserção externa dos entes da região amazônica a partir de 1997, e principalmente na década seguinte, como constatou Gomes Filho (2011). Além disso, ambas as políticas federais passaram a promover a dimensão subnacional como uma vertente complementar à execução das políticas nacionais, e as ações externas dos estados da região atuaram majoritariamente em convergência e colaboração com o ente central, em um processo de racionalização e segmentação da política externa (SOLDATOS, 1990; DUCHACEK, 1990). 
Esta ênfase na complementariedade da ação subnacional para política externa brasileira passou a ser aplicada nas políticas de proteção da Floresta Amazônica tanto em colaboração com o ente central quanto de forma autônoma, tornando os estados agentes ativos e essenciais nos esforços de preservação do ambiente, conforme constatou Fearnside (2016). Isso convergiu não somente com o referencial proposto, acerca da racionalização proposta por Soldatos (1990), mas também refletiu no desenvolvimento institucional dos entes federados da região para questões internacionais (MOREIRA, 2013).

Ao aplicar este debate aos projetos financiados pelo BID, aponta-se que de forma mediata identificaram-se complementariedades nos projetos de nível estadual e nacional. Uma vez que os projetos realizados através do Governo Federal tiveram como enfoque a abordagem de escala nacional sob a questão amazônica, sua execução em nível local depende da capacitação técnica dos aparatos estaduais. Assim, a ênfase em questões de fortalecimento institucional e cooperação técnica de agentes estatais e comunidades locais dos estados sobre gerenciamento e proteção da floresta amazônica acabou sendo parte do elemento indireto das medidas em nível nacional. Ademais, foi identificada uma intensificação dos investimentos do Banco diretamente nos estados a partir dos anos 2000, principalmente através de projetos de cooperação técnica, atuando diretamente com as secretarias estaduais, algo inexistente nos registros do BID anteriormente.

Percebeu-se assim um aumento dos investimentos de forma direta nos estados, algo anteriormente inexistente. A ênfase de tais projetos do BID na escala local ocorreu pela mitigação da degradação da floresta amazônica através do desenvolvimento comunitário e dos aparatos do estado. A complementariedade de tais projetos nos estados em relação aos projetos em nível federal relacionou-se, assim, com o debate da complementariedade na paradiplomacia à política externa nacional.

O segundo debate levantado, acerca da dimensão de políticas públicas que a política externa detém, defendida por Milani e Pinheiro (2013), ajudou a explicar como esta complementariedade temática dos projetos financiados pelo BID fortalece a dimensão subnacional da política externa. Observou-se que política externa passa a ser um contínuo das políticas domésticas devido à transversalidade das agendas e pluralidade de atores envolvidos (MILANI; PINHEIRO, 2013). Assim, o aumento dos investimentos do BID de forma direta nos entes subnacionais da região amazônica demonstrou o fortalecimento da dimensão subnacional pois tais investimentos têm como objetivo o desenvolvimento de pautas locais da agenda ambiental. Tanto pelo fortalecimento do aparato estatal subnacional, quanto pelos investimentos em capacitação técnica de comunidades e desenvolvimento humano, o que foi observado nos projetos patrocinados pelo Banco foi um enfoque nas políticas públicas dos estados como um instrumento de proteção mediata da Floresta.

Uma vez que os investimentos do Banco, analisados em forma comparativa entre os entes subnacionais e o Governo Federal, são complementares em seu objetivo final de combate ao desmatamento da floresta e desenvolvimento humano das comunidades locais, pode-se apontar que as estruturas construídas pela Diplomacia Federativa e a Cooperação Internacional Federativa atuaram de forma mediata neste processo. Inicialmente pelo Escritório regional, e posteriormente pelo engajamento nas políticas nacionais, o aumento registrado nos investimentos diretos do Banco nos estados converge temporalmente com a consolidação da Cooperação Internacional Federativa (2003), cujas políticas de apoio e assessoramento dos entes subnacionais refletiram no fortalecimento do aparato institucional dos estados da região (GOMES FILHO, 2011). Desta forma, esta última política ajudou a criar a dimensão subnacional a qual a paradiplomacia representa para a política externa brasileira, e o caso das medidas de proteção da Floresta Amazônica são um caso central para este entendimento.

Portanto, ao analisá-la perante o debate realizado e os dados levantados, percebeu-se a confirmação da hipótese. O aumento de investimentos diretos e complementares do BID nos estados da Amazônia Legal foi consequência mediata da Cooperação Internacional Federativa e a Diplomacia Federativa, visto que legitimaram politicamente os entes 
subnacionais na ação externa, como também os projetaram como uma dimensão complementar dos objetivos da política nacional.

\section{Comsiderações finais:}

O desenvolvimento argumentativo do presente trabalho visou responder ao problema de pesquisa acerca do fortalecimento da dimensão subnacional através dos investimentos do BID nos estados da Amazônia Legal. Para respondêlo, o estudo inseriu-se nos debates acerca da pluralização de atores na PEB e o caráter de política pública que a política externa detém. Ambos foram analisados a partir do referencial e da literatura de Análise de Política Externa, e considerando o papel da Diplomacia Federativa e da Cooperação Internacional Federativa como políticas federais de incentivo e coordenação ação externa subnacional.

O primeiro debate proposto foi explorado no trabalho através do papel cada vez mais relevante dos estados da região amazônica nas políticas brasileiras de preservação da Floresta. Os investimentos do BID analisados confirmaram o levantamento literário realizado, que apontou para os estados como agentes ativos na busca pelo financiamento das políticas e projetos de proteção da Floresta. Por sua vez, o segundo debate foi explorado ao realizar a análise dos investimentos do BID diretamente nos estados da região amazônica. Uma vez que tais investimentos se direcionaram majoritariamente a projetos de desenvolvimento humano e comunitário, a dimensão de políticas públicas da política externa fica mais visível através da escala local, no qual o combate ao desmatamento e o gerenciamento florestal são realizados pelo incentivo e capacitação de comunidades locais.

Os resultados objetivos da hipótese apresentada apontaram para o papel central das políticas da Diplomacia Federativa e da Cooperação Internacional Federativa no fortalecimento dos estados da Amazônia Legal em suas ações internacionais e busca por investimentos. A primeira política, pela construção de um escritório regional do Itamaraty na região Norte do país, e a segunda, pelo engajamento dos entes subnacionais na estratégia de desenvolvimento nacional do país garantiram aos estados daquela região o apoio institucional necessário para tornarem-se agentes internacionais nas políticas de proteção da Floresta.

Os resultados obtidos no desenvolvimento deste trabalho apontaram para a crescente complexidade que é a relação entre proteção ambiental e desenvolvimento social nos estados da Amazônia Legal. A ação externa destes estados, principalmente na obtenção de recursos para estas duas agendas, demonstrou o caráter único que esta região do Sul global apresenta. Além disso, a questão subnacional da região apontou para um novo locus de poder, cuja descentralização da ação externa abre portas para novas dinâmicas transnacionais envolvendo os entes locais.

Desta forma, notou-se que a questão subnacional serviu para suscitar um debate acerca do monopólio da política externa pelo governo central, e o caso brasileiro mostra-se como importante avanço institucional na construção de políticas de Estado que lidem com a ação externa subnacional (VIGEVANI, 2006). O mesmo pensamento é compartilhado por Banzatto (2015), destacando que a abertura do processo de formulação da política externa brasileira a outros atores foi essencial para o fortalecimento da inserção internacional de governos subnacionais, que passam a ser um ambiente institucional propício para expor suas demandas.

\section{Referências}

BANZATTO, Arthur Pinheiro de Azevedo. A Inserção Internacional dos Governos Subnacionais brasileiros através da Diplomacia Federativa e da paradiplomacia. Trabalho apresentado no $5^{\circ}$ Encontro Nacional da ABRI 29 a 31/07/2015, Belo Horizonte - MG. 2015

BEZERRA, Joana Carlos. O papel do Meio Ambiente na Política Externa Brasileira. Idéias. Campinas, n. 6 (nova série), $1^{\circ}$ semestre, 2013, p. 151-173.

BRANCO, Álvaro Chagas Castelo. Paradiplomacia e Entes Não-centrais no Cenário Internacional. $1^{\circ}$ ed. (ano 2008 ), $1^{\circ}$ reimpr. Curitiba: Juruá, 2011. 156p. 
BRASIL. Resenha de Política Exterior do Brasil.Ministério das Relações Exteriores. Número 76, $1^{\circ}$ semestre de 1995, ano 21, ISSN 0101 2428. Disponível em: <funag.gov.br/chdd/images/Resenhas/RPEB_76_jan_jun_1995.pdf>. Acesso em::30 nov. 2019.

BUENO, Ironildes. Paradiplomacia Contemporânea: Trajetórias e Tendências da atuação Internacional dos Governos Estaduais do Brasil e dos Estados Unidos. Tese em Relações Internacionais. Universidade de Brasília - UnB. Instituto de Relações Internacionais, 2010. 330p.

CORNAGO, Noe. On the Normalization of Sub-State Diplomacy. The Hague Journal of Diplomacy, vol. 5, p. 11-36. 2010.

DUCHACEK, Ivo D. Perforated sovereignties: toward a typology of new actors in international relations. In: MICHELMANN, Hans J. and SOLDATOS, Panayotis. Federalism and international relations: the role of subnational units. New York: Oxford University Press, 1990.

FARIA, Carlos Aurélio Pimenta de. Itamaraty e a Política Externa Brasileira: Do Insulamento à Busca de Coordenação dos Atores Governamentais e de Cooperação comos Agentes Societários. Contexto Internacional. Rio de Janeiro, vol. 34, no 1, janeiro/junho 2012, p. 311-355.

FEARNSIDE, P.M. Environmental policy in Brazilian Amazonia: Lessons from recent history. Novos Cadernos NAEA, Belém,19 (1), 2016, p. 27-46.

FIGUEIRA, Ariane Roder. Rupturas e continuidades no padrão organizacional e decisório do Ministério das Relações Exteriores. Rev. Bras. Polít. Int., Brasília, 53 (2), p. 5-22. 2010.

GOMES FILHO, Francisco. A Paradiplomacia Subnacional no Brasil: uma Análise da Política de Atuação Internacional dos Governos Estaduais Fronteiriços da Amazônia. Tese de Doutorado. Programa de Pós-Graduação em Relações Internacionais da Universidade de Brasília - UnB. Brasília, 2011. 276p.

GOMES FILHO, F.; VAZ, A.C. A paradiplomacia no contexto da Amazônia Brasileira: estratégias de desenvolvimento regional no Estado de Roraima. Amazônia: Ci. \&Desenv., Belém, v. 4, n. 7, jul./dez. 2008.

HOCKING, B. Regionalism: an international lrelations perspective. In: KEATING, M.; LOUGHLIN, J. (Eds.). The political economy of regionalism. London: Frank Cass, 1997. p. 90-111.

INTER-AMERICAN DEVELOPMENT BANK. Project Profile. Inter-American Development Bank, 2013. Disponível em: idbdocs.iadb.org/wsdocs/getdocument.aspx?docnum=EZSHARE-1010290490-19. Acesso em: 10 nov. 2019.

INTER-AMERICAN DEVELOPMENT BANK. PROGRAMA DE DESENVOLVIMENTO SUSTENTÁVEL DO ACRE - PDSA II. Secretaria de Estado de Planejamento do Estado do Acre, 2012. Disponível em: idbdocs.iadb.org/wsdocs/getdocument.aspx?docnum=EZSHARE 1030308089-3. Acesso em 10 de novembro de 2019.

INTER-AMERICAN DEVELOPMENT BANK. BR-T1194. Improving Tropical Forest Management as a Strategy for CC Mitigation. InterAmerican Development Bank, 2011. Disponível em: https://www.iadb.org/pt/project/BR-T1194. Acesso em 10 de novembro de 2019.

INTER-AMERICAN DEVELOPMENT BANK. TC0001015: ForestryEvaluation in theStateof Acre. Inter-American Development Bank, 2019. Disponível em: https://www.iadb.org/pt/project/TC0001015. Acesso em 10 dezembro de 2019.

INTER-AMERICAN DEVELOPMENT BANK. TC0003042: StrengtheningExtractiveActivities Acre. Inter-AmericanDevelopment Bank, 2019a. Disponível em: https://www.iadb.org/pt/project/TC0003042. Acesso em 10 dezembro de 2019.

INTER-AMERICAN DEVELOPMENT BANK. TC9703184: Sustainable Use Tropical Forest in Acre. Inter-American Development Bank, 2000. Disponível em: https://www.iadb.org/pt/project/TC9703184. Acesso em 10 dezembro de 2019.

INTER-AMERICAN DEVELOPMENT BANK. Sustainable Use ofthe Tropical Forest in Acre: Operation No. ATN/JF-6980-BR. InterAmerican Development Bank, 2000a. Disponível em: idbdocs.iadb.org/wsdocs/getdocument.aspx?docnum=EZSHARE-1207372386235. Acesso em 10 dezembro de 2019.

INTER-AMERICAN DEVELOPMENT BANK. BR-T1275: Linking climate change mitigation to community based forest management in Amapá. Inter-American Development Bank, 2013a. Disponível em: https://www.iadb.org/pt/project/BR-T1275. Acesso em 10 dezembro de 2019.

INTER-AMERICAN DEVELOPMENT BANK. TCABSTRACT - Linking Climate Change Mitigation and Adaptation in the Forests of Amapá, BR-T1275. Inter-American Development Bank, 2012a. idbdocs.iadb.org/wsdocs/getdocument.aspx?docnum=EZSHARE-1034491201-3. Acesso em 10 dezembro de 2019.

INTER-AMERICAN DEVELOPMENT BANK. TC9701443: Environmental Conservation in Tocantins. Inter-American Development Bank, 2019b. Disponível em: https://www.iadb.org/pt/project/TC9701443. Acesso em 10 dezembro de 2019.

INTER-AMERICAN DEVELOPMENT BANK. BRX1028: Low Carbon Agriculture and Avoided Deflorestation for reducing Poverty. InterAmerican Development Bank, 2013b. Disponível em: https://www.iadb.org/pt/project/BR-X1028. Acesso em 10 dezembro de 2019. 
INTER-AMERICAN DEVELOPMENT BANK. BR-T1287: Planning and Capacity Building of theTransition Fund for ARPA for Life. InterAmerican Development Bank, 2013c. Disponível em: https://www.iadb.org/pt/project/BR-T1287. Acesso em 10 dezembro de 2019.

INTER-AMERICAN DEVELOPMENT BANK. TC ABSTRACT. Inter-American Development Bank, 2013d. Disponível em: idbdocs.iadb.org/wsdocs/getdocument.aspx?docnum=EZSHARE-200512749-2. Acesso em 10 de dezembro de 2019.

INTER-AMERICAN DEVELOPMENT BANK. BRT293: Planing and Capacity Building of theTransition Fund for ARPA for Life. InterAmerican Development Bank, 2013e. Disponível em: https://www.iadb.org/pt/project/BR-T1293. Acesso em 11 novembro de 2019.

INTER-AMERICAN DEVELOPMENT BANK. BR-T1284: Assessment of the Impacts of Climate on the Stability of the Amazon Rainforest. Inter-AmericanDevelopment Bank, 2013f. Disponível em: https://www.iadb.org/pt/project/BR-T1284. Acesso em 11 novembro de 2019.

INTER-AMERICAN DEVELOPMENT BANK. TC ABSTRACT. Inter-American Development Bank, 2013g. Disponível em: idbdocs.iadb.org/wsdocs/getdocument.aspx?docnum=EZSHARE-1169965205-2. Acesso em 11 dezembro de 2019.

INTER-AMERICAN DEVELOPMENT BANK. BR-T1014: Program to Support the Amazon Protection System. Inter-American Development Bank, 2005. Disponível em: https://www.iadb.org/pt/project/BR-T1014. Acesso em 15 dezembro de 2019.

KINCAID, John. Constituent diplomacy in federal politics and the Nation-state: conflict and cooperation. In: MICHELMANN, Hans J. e SOLDATOS, Panayotis. Federalism and international lrelations: the role of subnational units. New York: Oxford University Press, 1990.

KEATING, Michael. Regiones y asuntosinternacionales: motivos, oportunidades estrategias. In: VIGEVANI, Tullo; WANDERLEY, Luiz Eduardo; BARRETO, Maria Inês e MARIANO, Marcelo Passini (orgs.). A dimensão subnacional e as relações internacionais. São Paulo: EDUC, Editora UNESP, EDUSC, FAPESP, 2004.

MEIRELLES, Thiago de O. Da Diplomacia federativa à cooperação internacional federativa. Dissertação de Mestrado em Ciência Política. São Paulo: Universidade de São Paulo. Programa de Pós-Graduação em Ciência Política da Universidade de São Paulo, 2016.

MIKLOS, Manoela S. A inserção internacional de unidades subnacionais percebida pelo estado nacional: a experiência brasileira. Dissertação de Mestrado em Ciência Política. São Paulo: Universidade Estadual Paulista, Programa de Pós-Graduação em Relações Internacionais San Tiago Dantas, 2010.

MIKLOS, Manoela. Diplomacia Federativa: $O$ estado brasileiro e a atuação internacional de suas unidades constituintes. Trabalho presentado ao 3o Encontro Nacional da Associação Brasileira de Relações Internacionais (ABRI), São Paulo, 2011.

MILANI, Carlos R. S.; PINHEIRO, L. Política externa brasileira: os desafios de sua caracterização como política pública. Contexto Internacional, Rio de Janeiro, v. 35, n. 01, p. 11-41, 2013.

MOREIRA, Paula Gomes. Governos subnacionais amazônicos: novos padrões de relacionamento na conjuntura internacional contemporânea. Contexto internacional, Rio de Janeiro , v. 35, n. 1, p. 105-137, Junho 2013 . Disponível em: http://www.scielo.br/scielo.php?script=sci_arttext\&pid=S0102-85292013000100004\&lng=en\&nrm=iso. Acesso em 10 de dezembro de 2019.

NUNES, Carmem J. S. A paradiplomacia no Brasil: o caso do Rio Grande do Sul. Dissertação de Mestrado em Relações Internacionais. Universidade Federal do Rio Grande do Sul. Porto Alegre, 2005.

PRADO, Henrique Sartori de Almeida. The Paradiplomacy in the regional integration process: the case of MERCOSUL. Conjuntura Austral, Porto Alegre, RS, v. 5, n. 21-22, p. 103-123, mar. 2014. ISSN 2178-8839. Available at: <https://seer.ufrgs.br/ConjunturaAustral/article/view/37162/28599>. Date accessed: 12 apr. 2021. doi:https://doi.org/10.22456/2178$\underline{8839.37162 .}$

SALOMÓN, M.; PINHEIRO, Leticia. Análise de Política Externa e Política Externa Brasileira: Trajetória, Desafios e Possibilidades. Revista Brasileira de Política Internacional, Brasília, v. 56, n. 01, p. 40-59, 2013.

SALOMÓN, Mónica. A dimensão subnacional da política externabrasileira: determinantes, conteúdos e perspectivas. In: PINHEIRO, Leticia; MILANI, Carlos R.S. Política externa brasileira: a política das práticas e as práticas da política. $1^{\circ}$ ed. Rio de Janeiro: Editora FGV. 2011.

SILVA, André. Do otimismo liberal à globalização assimétrica: a política externa do governo Fernando Henrique Cardoso (1995 2002). 1. ed. Curitiba: Juruá, 2009.

SOLDATOS, Panayotis. "An explanatory framework for the study of federated states as foreign-policy actors”. In: MICHELMANN, Hans J. e SOLDATOS, Panayotis. Federalism and international relations: the role of subnational units. New York: Oxford University Press, 1990.

SOMBRA SARAIVA, José Flávio. A busca por um novo paradigma: política exterior, comércio externo e federalismo no Brasil. Revista Brasileira de Política Internacional, Brasília, n47, n.02, 2004, pp. 131-162.

SOUZA, Elany Almeida. Emergências Globais do Clima: soberania e a gepolítica ambiental sul-americana. Conjuntura Austral, Porto Alegre, RS, v. 10, $\quad$ n. $\quad 52, \quad$ p. $59 \quad-\quad 79$, dec. $2019 . \quad$ ISSN $2178-8839 . \quad$ Available at: 
<https://seer.ufrgs.br/ConjunturaAustral/article/view/95206/55385>. Date accessed: 12 apr. 2021. doi:https://doi.org/10.22456/21788839.95206.

TAVARES, Rodrigo. Paradiplomacy: cities and states as global players. Nova York: Oxford University Press. 2016.

VIGEVANI, Tullo. Problemas para a atividade internacional das unidades subnacionais: São Paulo e o contexto brasileiro. In: Primeiro Relatório Científico da Pesquisa "Gestão pública e inserção internacional das cidades. São Paulo: CEDEC/UNESP/PUC-SP/FGVFAPESP, 2006.

\begin{tabular}{ll}
\hline Funções de colaboração exercidas & \\
\hline André Luiz Reis da Silva: & $\begin{array}{l}\text { Metodologia; Validação; Curadoria de dados; Administração do projeto; Visualização; Análise formal; Supervisão; Escrita } \\
\text { (revisão e edição); }\end{array}$ \\
Felipe de Macedo Teixeira: & $\begin{array}{l}\text { Conceituação; Metodologia; Validação; Curadoria de dados; Administração do projeto; Visualização; Análise formal; } \\
\text { Investigação; Escrita (primeira redação); Escrita (revisão e edição); }\end{array}$ \\
\hline & \multicolumn{1}{c}{ Informaçôesfornecidas pelos autores de acordo com a Taxonomia de Funçães de Colaborador (CRediT) }
\end{tabular}

